\title{
Interculturalidade, Descolonização e a Educação Superior Indígena no Brasil
}

Interculturality, Decolonization and Indigenous Higher Education in Brazil

Interculturalidad, Descolonización Y La Educación Superior Indígena En Brasil

Interculturalité, décolonisation et enseignement supérieur autochtone au Brésil

\section{ANA ELISA RODRIGUES ALVES RIBEIRO¹, REGINA CÉLIA DE SOUZA BERETTA²}

${ }^{1}$ Universidade de Franca

2 Universidade de Franca

\begin{abstract}
RESUMO: Objetivo e método. Este trabalho se propôs reflexionar teoricamente como ocorreu e como ocorre a construção intercultural nas Instituições de Ensino Superior, também em uma abordagem da descolonização do saber nesses espaços. Referencial teórico. Em educação, a perspectiva etnocêntrica de imposiçoes históricas da cultura europeia sobre outras, de saberes validados socialmente, inclusive se tratando de linguagens se contrapõe à interculturalidade. No Brasil, a formação superior indígena se deu por meio de políticas afirmativas, no provimento de vagas que englobassem aspectos raciais e sociais. Conclusões. No sentido de modificar estruturas de poder, o empoderamento indígena pode ser utilizado também com relação à construção dessas novas perspectivas no setor da educação, na forma do encontro e de um acordo comum, na construção de novos mundos por meio da interculturalidade.
\end{abstract}

DESCOLONIZAÇÃO. DIREITOS HUMANOS EMPODERAMENTO. INTERCULTURALIDADE. POVOS INDÍGENAS.

\begin{abstract}
Objectives and methods. The present study, proposes reflect theoretically how this intercultural construction occurs in higher education institutions, also including a decolonization perspective in this spaces. Background. In education, historic impositions of ethnocentric perspective from European culture on others, of accepted social knowledge's, including languages oppose interculturality. In Brazil, indigenous higher education happened by affirmative policies, offering limited places in universities according racial and social parameters. Conclusions. In the sense of change power structures, indigenous empowerment can also contribute to these new perspectives in educational sector, in meeting and common agreement, new world's construction through interculturality.

DECOLONIZATION. HUMAN
INTERCULTURALITY. INDIGENOUS.

RIGHTS. EMPOWERMENT.
\end{abstract}

Os autores cedem à Revista Internacional Educon os direitos de primeira publicação do presente artigo. Aplicam-se os termos de uma licença Creative Commons Atribuição 4.0 Internacional (CC BY 4.0), que permite o uso irrestrito, a distribuição e a reprodução em qualquer meio desde que a publicação original seja corretamente citada. 
RESUMEN: objetivo y métodos. Este trabajo tuvo como objetivo reflexionar teóricamente sobre cómo se produjo esta construcción intercultural en las instituciones de educación superior, también en un enfoque para la descolonización del conocimiento en estos espacios. Referencias teóricas. Em educación, la perspectiva teocéntrica de las imposiciones históricas de la cultura europea sobre otros, del conocimiento socialmente validado, incluso en el caso de las lenguas, se opone a la interculturalidad. En Brasil, la educación superior indígena se llevó a cabo a través de politicas afirmativas, al proporcionar vacantes que incluian aspectos raciales y sociales. Conclusión. En el sentido de modificar las estructuras de poder, el empoderamiento indigena también se puede utilizar en relación con la construcción de estas nuevas perspectivas en el sector educativo, en forma de una reunión y un acuerdo común, en la construcción de nuevos mundos a través de la interculturalidad.

\title{
DESCOLONIZACIÓN. DERECHOS HUMANOS. EMPODERAMIENTO. INTERCULTURALIDAD. PUEBLOS INDÍGENAS.
}

\begin{abstract}
RÉSUMÉ: objectif et méthode. Ce travail vise à refléter théoriquement comment cela s'est passé et comment se déroule la construction interculturelle dans les établissements d'enseignement supérieur, également dans une approche de la décolonisation des connaissances dans ces espaces. Référence théorique. Dans l'éducation, la perspective ethnocentrique des impositions historiques de la culture européenne aux autres, des connaissances socialement validées, même dans le cas des langues, s'oppose à l'interculturalité. Au Brésil, l'enseignement supérieur autochtone s'effectuait dans le cadre de politiques positives, en offrant des postes vacants comportant des aspects raciaux et sociaux. Conclusions. Afin de modifier les structures de pouvoir, l'autonomisation autochtone peut également être utilisée en relation avec la construction de ces nouvelles perspectives dans le secteur de l'éducation, sous la forme d'une rencontre et d'un accord commun, dans la construction de nouveaux mondes par l'interculturalité.

\section{DESOLONISATION. DROITS DE L'HOMME. AUTORISATION. INTERCULTURALITÉ. PEUPLES AUTOCHTONES.}

\section{Introdução}

Tendo por ponto de partida o "encontro" intercultural como um acontecimento que não se dá sem desigualdades de forças, pode-se considerar que a perspectiva do poder na relação do contexto dos povos indígenas brasileiros sempre os colocou como "minorias", consideradas como "grupos ideologicamente menos poderosos" (ACSELRAD, 2006).

Ao longo da história estes povos originários passaram de um número elevado para quantidades menos significativas no total da população, e que também estiveram em condição de menos valia nas relações de poder, um aspecto que pode justificar os seus atuais perfis sociais fragilizados (RIBEIRO, 2006).

Além das questões de dominação e colonização para com esses povos, é preciso também abordar outras perspectivas, e contrapor o significado de "encontro", abordando-o sob a ótica da interculturalidade. A interculturalidade, como uma interação dinâmica entre grupos considerados culturalmente diversos, para ser efetiva exibe também o desejo de comunicação de ambas as partes, e porque não dizer de um acordo comum. Monteiro (2006, p. 26), a respeito do contato entre missionários e indígenas no país, relata: "Tendo em vista que versões contrastantes sobre o mundo são irredutíveis umas às outras, uma construção de mundo inter-relacional se produz nos jogos de linguagem”.

Historicamente, verifica-se que, justamente por meio destes movimentos de ajustes comuns, de experiências e linguagens, os diversos povos indígenas brasileiros ainda permanecem presentes, diferentemente de outros modelos colonizadores. A interculturalidade, nesse sentido, configura-se, de certa maneira, como uma forma de resistência, exemplificando a forma como os diversos povos indígenas 
se apropriaram e se apropriam de representações, que não lhes são próprias, configurando novas perspectivas (MONTEIRO, 2006).

A interculturalidade e a produção deste acordo com uma disposição para a comunicação foram descritas por Wittgenstein, em 1975, como o compartilhamento de experiências comuns, em familiaridades, em meio ao contraste cultural. Pensando no histórico nacional, em um espaço de disputa territorial constante entre diversos atores, é possível verificar esse campo de necessidade de comunicação e experiências comuns, entre povos indígenas e não indígenas, que produziriam a configuração territorial atual, em uma construção contínua de "novos-mundos", desde 1500, até os dias atuais.

Nesse mesmo sentido, pode-se compreender o encontro intercultural no contexto educacional como uma modalidade comunicativa. Em educação, a interculturalidade se apresenta na forma do encontro, e também possui a perspectiva das imposições históricas da cultura europeia sobre a cultura nativa, de saberes soberanos e validados socialmente, inclusive se tratando de linguagens e idiomas.

O idioma é o espírito e o veículo da dimensão afetiva das culturas. Reconhecer que os "outros" também possuem conhecimentos é admitir o valor e a pertinência de suas culturas e, também, outorgar-lhes uma posição de interlocutores. Todas essas são premissas fundamentais para se construir o diálogo intercultural como fundamento democrático da educação (MARIN, 2009, p. 17).

Novas conformações vêm se organizando a partir de uma abertura para estes povos junto às Instituições de Ensino Superior (IES). Atualmente, a população indígena representa $0,42 \%$ da população do país e é distribuída entre 305 etnias e falantes de 274 línguas, com cerca de 315 mil indivíduos vivendo nas cidades e 502 mil em aldeias, com indivíduos que permeiam diversos espaços sociais, inclusive nas IES, produzindo acordos e questionando poderes, em uma dinâmica viva e nova (ISA, 2018).

\section{Objetivos}

Dialogando com Monteiro (2006), a dinâmica intercultural presume uma contínua construção e desconstrução de códigos comunicativos, com base nas culturas locais, em diversas instâncias sociais. Neste trabalho se propõe reflexionar teoricamente como ocorreu e como ocorre essa construção intercultural no setor da educação, mais especificamente nas Instituições de Ensino Superior (IES), também em uma abordagem da descolonização do saber nesses espaços.

\section{Fudamentação Teórica}

Segundo o IBGE (2010), nas IES, a diferença entre os brasileiros de 25 anos ou mais com ensino superior concluído foi de 4,7\% de negros e 5,3\% de pardos contra 15,0\% de brancos, sendo a categorização indígena inexistente. A Lei Federal no 12.711 promulgada em 2012, reserva vagas nas universidades, combinando frequência à escola pública, renda e cor (etnia), o que possibilitou um encontro intercultural e também de resistência de saberes no ambiente educacional das IES no Brasil. Essa busca pelo acesso ao setor da educação significa, de certa maneira, uma efetivação de direitos, em resposta a dívida histórica de exclusão e discriminação dos povos originários, e também de uma necessidade de "comunicação" e "acordo".

Colocando a interculturalidade como perspectiva de desconstrução de uma hierarquização histórica, a implicação dos envolvidos na construção de "novos mundos" pode ocorrer constantemente também no ambiente acadêmico. O desafio epistemológico consiste no reconhecimento da existência de outras visões de mundo, da validade de outros conhecimentos e outras formas de construir conhecimentos. Comunicação e ressignificações das "tradições" fazem desse encontro uma forma nova e dinâmica de construção de novos saberes, tanto para os grupos de estudantes, também para as IES e 
sociedade, no exercício do respeito, cidadania e democracia. Entretanto, as tensões de lidar com saberes ocidentais, já consagrados socialmente em diálogo com os saberes milenares existentes nas culturas tradicionais dos diversos povos indígenas do Brasil, exacerbam o processo em que se deu a colonização (MONTEIRO, 2006; MARIN, 2009).

O esforço revolucionário de transformação radical destas estruturas não pode ter, na liderança, homens do quefazer e, nas massas oprimidas, homens reduzidos ao puro fazer.

Este é um ponto que deveria estar exigindo de todos quantos realmente se comprometem com os oprimidos, com a causa de sua libertação, uma permanente e corajosa reflexão.

Se o compromisso verdadeiro com eles, implicando na transformação da realidade em que se acham oprimidos, reclama uma teoria da ação transformadora, este não pode deixar de reconhecer-lhes um papel fundamental no processo da transformação.

Não é possível à liderança tomar os oprimidos como menos fazedores ou executores de suas determinações; como menos ativistas a quem negue a reflexão sobre o seu próprio fazer. Os oprimidos tendo a ilusão de que atuam, na atuação da liderança, continuam manipulados exatamente por quem, por sua própria natureza, não pode fazê-lo.

Por isto, na medida em que a liderança nega a práxis verdadeira aos oprimidos, se esvazia, consequentemente, na sua.

Tende, desta forma, a impor sua palavra a eles, tornando-a, assim, uma palavra falsa, de caráter dominador.

Instala, com este proceder, uma contradição entre seu modo de atuar e os objetivos que pretende, ao não entender que, sem o diálogo com os oprimidos, não é possível práxis autênticas, nem para estes nem para ela.

O seu quefazer, ação reflexão, não pode dar-se sem a ação e a reflexão dos outros, se seu compromisso é a libertação (FREIRE, 1974, p. 70).

No sentido de modificar estruturas de poder, promovendo a participação social e política desses povos, o termo empoderamento indígena pode ser utilizado também com relação à construção dessas novas perspectivas no setor da educação, em um processo dinâmico, cognitivo, afetivo e condutural para os diversos povos envolvidos, e também como produto final das IES, no intuito de transformar estruturas perversas historicamente construídas, e trabalhar a descolonização de saberes (BUSS, 2000; OLIVEIRA, 2016).

A participação desses povos na construção do próprio processo pedagógico acadêmico, dialogando com Freire, 1974, é condição sine qua non para que os processos colonizadores não se perpetuem também na IES, e as políticas afirmativas sejam verdadeiramente transformadoras da realidade constatada em suas premissas. Nesse sentido, o empoderamento indígena, por meio da conscientização de sua condição oprimida e de exclusão na construção diretiva acadêmica e a retomada destes espaços por meio do quefazer, tornando-os atores, pode favorecer a interculturalidade.

Roso \& Romanini, em seu ensaio teórico sobre empoderamento individual, empoderamento comunitário e conscientização, também trouxeram um paralelo entre esses conceitos e a pedagogia da libertação (ROSO; ROMANINI, 2014), dialogando com a proposta de formação superior indígena no sentido de que esta pode ser uma ferramenta de promoção do ato social de libertação e transformação social, por meio dos passos individuais e coletivos no processo de consicientização. O empoderamento e a interculturalidade, se estiverem presentes no ambiente das IES, podem promover a participação social e política indígena a partir do fortalecimento dos sujeitos nos três níveis: psicológico ou individual, grupal ou organizacional e estrutural ou político (FREIRE; GADOTTI; GUIMARÃES, 1995; KLEBA; WENDAUSEN, 2009; BUSS, 2010).

Na Psicologia Social, na Educação, nas Ciências Sociais e na Saúde o termo empoderamento comunitário é trabalhado como desdobramento do primeiro conceito, valorizando o nível grupal no processo de busca da transformação social, o que precisa ser considerado quando se propõe a trabalhar 
a inclusão indígena na formação superior, pelos aspectos culturais desses grupos na tomada de decisões e vida coletiva (RIBEIRO, 2006; ROSO; ROMANINI, 2014).

Assim, sob uma perspectiva da teoria da mediação cultural, a questão do poder, implícito no trabalho educativo, não pode ser reduzida à dominação colonial, uma vez que gera "produção cultural". O empoderamento, neste sentido, se dá na interlocução dos grupos, com uma dimensão políticoideológica dos indivíduos e grupos indígenas, que buscam a formação, para além da reinvindicação de direitos e reconhecimentos. Existe nessa teoria uma transformação destes próprios povos, também em uma ressignificação de sua própria cultura e de alteridade, não sendo categorizada como perda da cultura original, ou imposição de valores ocidentais (MONTEIRO, 2006).

$\mathrm{Na}$ busca de uma perspectiva intercultural que admita a igualdade dos conhecimentos, para além de toda categorização e hierarquização que nos foram impostas pelo etnocentrismo da dominação cultural ocidental, a perspectiva intercultural pode nos permitir revalorizar os saberes locais e criar as condições para compartilhá-los em uma perspectiva de complementaridade, que vá para além da mesquinha realidade da lógica do saber, traduzido como poder e como dominação. Trata-se de associar os conhecimentos produzidos pelo Ocidente, com os conhecimentos produzidos pelas culturas tradicionais, locais ou regionais, considerando seus contextos de produção (MARIN, 2009, p. 20).

Considerando contextos ampliados, as normativas resultantes dos movimentos globais pela educação em direitos humanos, de princípios de respeito à diversidade e à sustentabilidade socioambiental, no intuito de superar as desigualdades educacionais, promover a cidadania e erradicar a discriminação; dizem respeito aos compromissos atuais assumidos pelo Brasil, junto à diversas nações, nos 17 Objetivos-metas de Desenvolvimento Sustentável (ODS) para 2030, e corroboram com estas facetas da formação superior indígena (ONUB, 2018).

Os direitos humanos fundamentais, e a possibilidade dessa associação de conhecimentos, construindo um "novo mundo", ou uma terceira perspectiva, é justificativa incontestável para a cota social/racial, como reserva de um número vagas em instituições de ensino com o objetivo de igualdade por meio da equidade. Entretanto, mais do que o provimento de vagas, o processo de formação superior indígena e também os resultados do mesmo para indivíduos, suas comunidades, e estruturas sociais historicamente construídas, revelam um horizonte de necessidades e possibilidades (FRIAS, 2013).

\section{Argumentação}

Em 2009, a Organização das Nações Unidas para a Educação, a Ciência e a Cultura (UNESCO), com o relatório intitulado "Investir na diversidade cultural e no diálogo Intercultural" ressaltou a complexidade dessa proposta, não estabelecendo uma solução simplesmente pela vontade política, mas na adoção de diretrizes comuns em diversos âmbitos da sociedade. O Brasil, desde 2003, por meio de políticas afirmativas, passou a incluir os diversos povos indígenas em políticas de acesso às IES e, mais recentemente, se alinhou a uma perspectiva global no compromisso assumido por meio da Agenda 2030, de respeito às diversidades e superação de desigualdades educacionais (FRIAS, 2013; ONUB, 2018).

Entretanto, apesar da implementação dessas normativas, é preciso caracterizar os espaços das IES e da educação formal, enquanto facetas de uma colonialidade que foi sentida principalmente por esses diversos povos. O Colonialismo, com seu fim político, permaneceu como colonialidade, caracterizada pela predominância de padrões eurocêntricos, nos diversos setores, como o econômico, sociocultural e epistêmico, negando independência a outras formas de pensar e viver, principalmente dos 
povos historicamente subjugados, não colocando fim às desigualdades e hegemonias, geradas no passado (FARIAS; FALEIROS, 2018).

Pensando nas IES e no acesso indígena a esses espaços, é preciso reconhecer que a colonialidade, junto aos movimentos de globalização e políticas neoliberais, reforçam modos etnocêntricos de existir, pensar e conceber a realidade. É preciso considerá-la desde sua perspectiva de poder, legitimando o lócus formal de aprendizagem, e ao mesmo tempo não legitimando (até caracterizando como inferiores) os saberes tradicionais indígenas. Essa epistemologia eurocêntrica se transforma, portanto, em uma colonialidade do Saber e do Ser, descreditando matrizes culturais diversas e seus conhecimentos produzidos, assim como suas potências enquanto grupos políticos, sociais, culturais e de direitos (FARIAS; FALEIROS, 2018).

A educação formal, nesse sentido, mesmo garantindo acesso, pode vir a ter caráter desumanizador e instrumental, apesar das políticas públicas do setor, enfatizarem o desenvolvimento de competências interculturais e o diálogo entre culturas e civilizações como prioridade (UNESCO, 2009).

A realidade das populações indígenas em trajetória acadêmica ainda é complexa, e necessita não só de outras políticas afirmativas, mas de mudanças sociais estruturais, que poderiam e deveriam vir a ser trabalhadas inclusive no setor. A inclusão deste público às IES não é suficiente e garantia de permanência, conclusão e até inclusão dos futuros profissionais indígenas no mercado de trabalho, pois existe uma barreira muito maior que leva muitos estudantes indígenas à evasão das IES (HERBETTA; NAZARENO, 2020).

No ambiente acadêmico, suas ontologias, seus conhecimentos e suas línguas não são sequer imaginados, pois para a maioria dos docentes dos cursos de graduação e pósgraduação essas dimensões no trato com os estudantes indígenas não são consideradas. Neste contexto, na maioria dos casos, o português é a segunda língua dos estudantes indígenas e, ao pertencerem a povos de tradição oral, possuem normalmente dificuldade em lidar com a escrita (HERBETTA; NAZARENO, 2020, p. 16).

A abordagem da diversidade e pluralidade nas instituições acadêmicas precisa ser repensada, uma vez que essas podem, inclusive, agudizar estruturas culturais históricas e de colonização.

[...]foi-se criando uma necessidade nos jovens nativos de apreender conceitos e teorias que não cabem no pensar holístico e circular de seus povos. Esta agressão ao sistema mental indígena, fruto de uma história da qual não somos culpados, mas sobre qual temos responsabilidade, acaba se perpetuando nas novas políticas inclusivistas levados [sic] a efeito por governos nas três esferas. Conclusão: nossos jovens se vêm [sic] obrigados a aceitar como inevitável à [sic] necessidade de ler e escrever códigos das [sic] quais prefeririam não aprender e não lhes é dado o direito de recusar sob a acusação de preguiça ou descaso para com a "boa vontade" dos governos e governantes (MUNDURUKU, 2017 apud HERBETTA; NAZARENO, 2020. p. 3-4).

Mignolo (2007) considerou a decolonialidade como aquela energia de não se deixar manejar por esta lógica da Colonialidade que, quando inserida na educação, envolve o ato de pensar e a busca por alternativas para construção de novos percursos sociais, que fujam de dicotomias e fortaleçam a interculturalidade.

A UNESCO, em seu $2^{\circ}$ Relatório Mundial, destacou a necessidade de investimentos na diversidade cultural e no diálogo intercultural, ressaltando, nesse sentido, a necessidade de olhar, sob perspectivas da interculturalidade, as diferenças entre culturas, enfatizando também a existência de uma permeabilidade das fronteiras culturais e o potencial criativo que o contato exerce nos grupos e indivíduos. Ao longo da história da humanidade foram justamente o diálogo e a comunicação, também trabalhados por 
Monteiro (2006), que resultaram diversas formas e práticas culturais atuais, inclusive em casos extremos como da escravatura, gerando intercâmbios e processos de aculturação inversa ou assimilação de aspectos também pela cultura dominante (UNESCO, 2009).

A interculturalidade se apresenta, assim, como um desafio e também uma possibilidade de mudança de uma estrutura rígida consolidada nas IES. Carvalho e Segato (2002 apud HERBETTA; NAZARENO, 2020. p. 9) exemplificaram que, apesar da universidade ser um dos poucos redutos de exercício do pensamento crítico, em nosso país, o desconhecimento e indiferença do mundo acadêmico para a perspectiva da justiça racial e da exclusão são constantes desde sua origem, não havendo jamais discussões sobre a composição elitizada dos cursos de direito, medicina, farmácia e engenharia.

Segundo Sastre (2009), a escola e o processo de ensino-aprendizagem não se dão de maneira independente da sociedade, pelo contrário, se apresentam como uma parte da mesma, que reproduz o todo das relações sociais. É, portanto, papel das instituições de educação trabalhar as injustiças sociais e ressignificar as relações sociais e de poder.

No Brasil, e no setor, a obrigatoriedade do estudo da história e cultura indígena, por meio da Lei Federal $n^{\circ} 11.645$, de 10 de março de 2008, nos estabelecimentos de ensino públicos e privados em todo o país, foi uma tentativa de se transformar padrões históricos de colonização e eurocentrismo. Esse marco político social representa apenas uma parte de diversas ações, em diversas políticas, para se trabalhar a questão étnica, o preconceito e as diferenças raciais no país. Mais especificamente, no caso do acesso da população indígena às IES, a ação afirmativa registrada a partir do projeto de Lei Federal no 180/2008 e aprovada em 2012 na forma da Lei Federal no 12.711/2012, resultou na possibilidade de reserva de vagas nas universidades para indígenas, combinando frequência à escola pública, renda e cor (etnia).

A despeito desses avanços, pode-se verificar que muito ainda tem que ser reconsiderado para que a formação acadêmica indígena nas IES esteja em uma perspectiva descolonizadora, e que se atinja uma proposta intercultural genuína. O contexto indigenista, de luta e resistência ao longo de toda a história, trouxe grandes pistas da capacidade de organização comunitária, da valorização cultural e formas de reivindicar direitos, além do seu próprio modo de organização frente ao contato intercultural (KLEBA; WENDAUSEN, 2009).

Farias e Faleiros, abordando a questão da educação no campo, que envolve trabalhadores do campo de modo geral, incluindo indígenas e os diversos assalariados, ressaltam que a inclusão na educação não está distante das lutas de classes.

[...]cabe lembrar que a Educação Rural, que estava relacionada com o desenvolvimento econômico, se firmou no começo dos anos 1930 e se potencializou durante o processo de industrialização nos anos 1950, 1960 e 1970, associada ironicamente com a Reforma Agrária, com o intuito de o Estado fornecer escolarização e formação técnicoprofissional para formar mão de obra qualificada e atuar no processo de industrialização e modernização do campo, garantindo que o desenvolvimento do capitalismo no campo pudesse ocorrer de forma mais intensa e rápida [...] essa concepção de ensino estava vinculada aos interesses da elite e às oligarquias agrárias, sob um projeto que tendia intensificar a submissão do trabalho ao capital, se opondo a formulação da educação como processo de emancipação. [...] provocando uma exclusão educacional desses sujeitos, anulando suas condições de existência, suas lutas e seus modos de vida e conferindo a eles funções e educação alienadoras para gerar mão de obra (FARIAS; FALEIROS, 2018, p. 8).

A interculturalidade, portanto, como resistência, exemplificada na forma como os diversos povos indígenas se apropriaram e se apropriam de representações que não lhes são próprias, configura novas perspectivas inclusive de empoderamento, predominantemente de característica coletiva e política. Esse empoderamento comunitário indígena, no respeito e apoio mútuo entre grupos e etnias, promove, assim, 
o sentimento de pertencimento, práticas solidárias e de reciprocidade; favorece e viabiliza a corresponsabilização e a participação social dos diversos povos na perspectiva da cidadania (BUSS, 2000; MONTEIRO, 2006).

A contrapartida ou até uma aculturação inversa é ainda uma grande barreira para os próprios indígenas e também para o setor educacional, que inclusive continua perpetuando estruturas perversas da sociedade. A questão cultural ainda permeia o espaço das IES no país, no que diz respeito ao acesso e permanência indígena, mas pode ser favorecida pela interculturalidade, se institucionalmente se permitir. "É possível que a dinâmica das manifestações culturais possa trazer vitalidade aos espaços públicos, conciliando perspectivas, dando voz a grupos e a associações, mesmo que heterogêneos. Nos diálogos interculturais, portanto, existem zonas de intermediação, que podem favorecer os rearranjos pessoais e sociais" (DANTAS, 2012, p. 67).

Verifica-se, assim, que a inclusão dos diversos povos indígenas nas IES revela questões mais profundas, em uma necessidade de transformação institucional, no intuito de se fazer uma educação superior baseada na problematização das questões indígenas vividas dentro e fora da academia, na crítica e conscientização da realidade e da própria educação bancária, capitalista ou eurocêntrica, incluindo a transformação dos próprios espaços acadêmicos para novas formas de construção de saberes (FARIAS; FALEIROS, 2018).

A genealogia do pensamento descolonial é pluriversal (não universal). Assim, cada nó da rede desta genealogia é um ponto de partida e abertura que reintroduz idiomas, memórias, economias, organizações sociais, subjetividades, esplendores e misérias dos legados imperiais. Hoje, reclama-se um pensamento descolonial que articule genealogias espalhadas pelo planeta (MIGNOLO, 2007 apud HERBETTA; NAZARENO, 2020, p. 21).

\section{Considerações Finais}

A educação indígena superior esbarra em aspectos de colonialidade do Saber e do Ser, mesmo 1500 anos depois, descreditando matrizes culturais indígenas diversas e seus conhecimentos, assim como suas potências enquanto grupos políticos, sociais, culturais e de direitos. A interculturalidade, como uma interação dinâmica, no desejo de comunicação e acordo de ambas as partes, favorece a consolidação da proposta de inclusão, direitos humanos e pagamento de dívidas históricas para com esses povos, em um movimento emancipatório.

O tema do acesso e permanência de populações indígenas na universidade é bastante novo nas discussões acadêmicas e provavelmente acompanha os próprios entraves desse contato mais expressivo no setor da educação. É preciso discutir profundamente e em uma perspectiva crítica, dando voz e empoderamento aos indígenas universitários e comunidades, revelar e viabilizar as necessidades de transformação institucional para a práxis da interculturalidade. 


\section{Referências}

Acselrad, M. Por uma visão crítica de minoria. Crítica cultural, v. 1, n. 1, jan. / jun. 2006.

Brasil. Lei 11.645, de 10 de marco de 2008. Recuperado em 10 jun. 2020, de http://www.planalto.gov.br/ccivil 03/ ato2007-2010/2008/lei/111645.htm.

Brasil. Lei 12.711/2012. Recuperado em 06 agos. 2020, de http://www.planalto.gov.br/ccivil 03/ ato2011-2014/2012/Lei/L12711.htm.

Cruz, C.S., Jesus, S.S. Lei 11.645/08: A escola, as relações étnicas e culturais e o ensino de históriaalgumas reflexões sobre essa temática no PIBID. XXVII Simpósio Nacional de História. Conhecimento Histórico e Diálogo Social. Natal, Rio Grande do Norte, 22-26 de julho de 2013

Dantas, S. D. (Org.). Diálogos Interculturais: Reflexões interdisciplinares e intervenções psicossociais, São Paulo: Instituto de Estudos Avançados da Universidade de São Paulo, 2012. ISBN: 978-85-63007$03-2$

Farias, M. \& N.; Faleiro, W. Movimento de educação do campo enquanto fenômeno decolonial: afirmando percursos de desobediência político-epistemológica. Decolonialidade e Interculturalidade Crítica - resistência e desobediência. Revista Educação e Cultura Contemporânea, v. 15, n. 39. 2018. http://dx.doi.org/10.5935/2238-1279.20180038

Freire, P. Pedagogia do oprimido. São Paulo: Paz e Terra, 1974.

Freire, P.; Gadotti, M. \& Guimarães, S. Pedagogia - Diálogo e conflito. 4. ed. São Paulo, SP: Cortez, 1995.

Herbetta, A.F \& Nazareno, E. Sofrimento acadêmico e violência epistêmica: considerações iniciais sobre dores vividas em trajetórias acadêmicas indígenas. Tellus, Campo Grande, MS, ano 20, n. 41, p. 57-82, jan./abr. 2020.

Instituto Socioambiental. ISA. Povos indígenas no Brasil: população indígena no Brasil. São Paulo, 2012. Recuperado em 11 maio, 2020, de http://pib.socioambiental.org/pt/c/0/1/2/populacaoindigena-no-brasil.

Kleba, M. E.; Wendausen, A. Empoderamento: processo de fortalecimento dos sujeitos nos espaços de participação social e democratização política. Saúde Soc. São Paulo, v. 18, n. 4, p.733-743, 2009.

Marin, J. Interculturalidade e descolonização do saber: relações entre saber local e saber universal no contexto da globalização. REP - Revista Espaço Pedagógico, Passo Fundo, v. 16, n. 1, p. 7-26, jan./jun. 2009.

Mignolo, W. El pensamiento decolonial: desprendimiento y apertura. Un manifiesto. In.: CastroGómez, S. \& Grosfoguel, R. (Org.). Prólogo. Giro decolonial, teoría crítica y pensamiento heterárquico. El giro decolonial: reflexiones para una diversidad epistémica más allá del capitalismo global. - Bogotá: Siglo del Hombre Editores, 2007. 
Monteiro, P. (Org). Deus na aldeia, missionários, índios e mediação cultural. São Paulo: Globo, 2006.

Munduruku, D. A escrita e a autoria fortalecendo a identidade. 2017. Recuperado em 04 de agosto, 2020, de https://pib.socioambiental.org/pt/A escrita e a autoria fortalecendo a identidade.

Organização das Nações Unidas para a Educação, a Ciência e a Cultura (UNESCO). $2^{\circ}$ Relatório Mundial da UNESCO: Investir na diversidade cultural e no diálogo intercultural (ISBN n ${ }^{\circ}$ 978- $^{-}$ 92-3-104077-1). 7 place de Fontenoy 75007 Paris, France. 2009

Ribeiro, D. O Povo Brasileiro: a formação e o sentido do Brasil. São Paulo: Companhia das Letras, 2006.

Roso, A.; Romanini, M. Empoderamento individual, empoderamento comunitário e conscientização: um ensaio teórico. Psicologia e Saber Social, v. 3, n. 1, p. 83-95, 2014.

Sastre, E. Panorama dos estudos sobre violência nas escolas no Brasil:1980 -2009. Recuperado em 11 de junho, 2020, de http://portaldoprofessor.mec.gov.br/storage/materiais/0000015503.pdf.

Wittgenstein, L. Investigações filosóficas, trad José Carlos Bruni. São Paulo: Abril Cultural, 1977.

\section{Sobre os Autores}

\section{RIBEIRO, ANA ELISA RODRIGUES ALVES}

(D) ORCID: https://orcid.org/0000-0002-8057-3049

Possui graduação em Odontologia pela Universidade de São Paulo (2011) e mestrado em Odontologia (Estomatologia Biologia Oral) pela Universidade de São Paulo (2015). Especialista em Homeopatia (2012) e Endodontia (2018). Realizou aperfeiçoamento profissional em Educação Permanente pela Fundação Osvaldo Cruz (2015). Atualmente é docente do curso de Odontologia da Universidade de Franca, doutoranda no Programa de Promoção de Saúde e pesquisadora participante do grupo de pesquisa CNPq "Populações Vulneráveis e a Promoção da Saúde".Tem experiência na área de saúde coletiva, odontologia para pacientes com necessidades especiais e odontologia clínica, atuando principalmente nos seguintes temas: educação, promoção da saúde, saúde indígena, pacientes com condições sistêmicas debilitantes e endodontia.

E-mail: analisa.rar@gmail.com / http://lattes.cnpq.br/3987280357922700

\section{BERETTA, REGINA CÉLIA DE SOUZA}

(D) ORCID: https://orcid.org/0000-0003-2817-0805

Possui graduação em Serviço Social pela Faculdade de Serviço Social de Araraquara (1979), graduação em pedagogia pela Federação das Faculdades Isoladas de Araraquara (1989),mestrado (2005) e doutorado (2010) em Serviço Social pela Universidade Estadual Paulista Júlio de Mesquita Filho- UNESP Franca. Foi docente da graduação e pós-graduação e coordenadora da extensão e pesquisa do Instituto Municipal de Ensino Superior de Bebedouro Vitorio Cardassi (IMESB) e do Centro Universitário da Fundação Educacional de Barretos,(UNIFEB). Prestou serviços como Consultora do Ministério do Desenvolvimento Social (MDS) e foi docente do SENAC.Coordenadora executiva aposentada da Prefeitura do Município de Araraquara. 
Secretaria Municipal de Assistência e Desenvolvimento Humano de Barretos(2013-2014).Tem experiência na área de Gestão Social, com pesquisas voltadas para os temas: criança e adolescente, famílias, direitos sociais. Atualmente docente/pesquisador da UNIFRAN do Programa de Pós Graduação de Strictu Sensu Promoção da Saúde. Pesquisador a do Núcleo de Estudos em Promoção da Saúde (NEP-PS) e do Grupo de Pesquisa em Promoção de Saúde. Membro do Comitê de Integridade em Pesquisa. da UNIFRAN. Líder do Grupo de pesquisa Populações vulneráveis e promoção da saúde (CNPQ). Linhas de pesquisa: 1) Politicas e práticas de promoção da saúde 2) Ambientes, tecnologias e sustentabilidade em promoção da saúde. E-mail: regina.beretta@unifran.edu.br / http://lattes.cnpq.br/9170733889633526.

Submetido: 07 ago. 2020

Aceito: 21 set. 2020 